intervention periods, a significant change in slope was observed for both lag time (coefficient $-8.85[95 \% \mathrm{Cl}-17.25,-0.44], \mathrm{p}=0.04$ ) and risk of treatment with biologics (coefficient -1.17 [95\% Cl -2.09, -0.24], $\mathrm{p}=0.01$ ). As expected in more recent years - according to a T2T approach - a monotonous positive trend in percentage of patients treated with biologics is also observed in EAC (coefficient $0.31[95 \% \mathrm{Cl} 0.05,0.58])$.

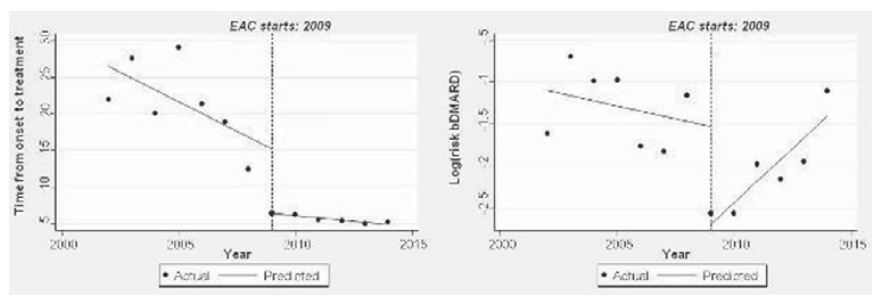

Conclusions: The implementation of an EAC that integrates care and applies tight control and standard of care, leads to early diagnosis and treatment and may lower the need - overtime - of second-line biologic drugs, with a significant impact both on individuals and health care systems.

Disclosure of Interest: None declared

DOI: 10.1136/annrheumdis-2017-eular.6481

\section{AB0228 IMMUNOLOGICAL APPROACH TO THE DIAGNOSIS OF LESIONS OF THE NERVOUS SYSTEM IN PATIENTS WITH RHEUMATOID ARTHRITIS}

I.P. Gontar ${ }^{1}$, E.V. Baranov ${ }^{1}$, L.A. Maslakova ${ }^{1}$, A.S. Trofimenko ${ }^{1}$ O.V. Paramonova ${ }^{2} .{ }^{1}$ Clinical Immunology Lab, FSBSU Research Institute for Clinical and Experimental Rheumatology; ${ }^{2}$ Department of Hospital Therapy, Volgograd State Medical University, Volgograd, Russian Federation

Background: Although $\mathrm{S} 100$ proteins represent $40 \%$ of the neutrophil cytoplasmic proteins, their physiological and pathological functions are still unclear. S100 protein concentrations are dramatically enhanced in synovial fluid and synovium of patients suffering from rheumatoid arthritis (RA). Their expression seems to correlate with disease activity and joint damage [1]

Objectives: Improvement of immunological detection of neurological involvement in RA by means of polyacrylamide magnetic beads with immobilized S- 100 protein.

Methods: The research was carried out in agreement with the principles of the World Medical Association Declaration of Helsinki. The informed consent had been signed by all involved persons, another obligate requirement was age 18 years or more. The patients were from the rheumatologic wards in Volgograd Municipal Hospital No. 25 and Volzhsky Municipal Hospital No. 1. Diagnosis of RA was established by ACR-EULAR criteria (2010), RA activity was evaluated using DAS28. Serum anti-S-100 protein antibodies were measured by ELISA, with S-100 protein immobilized on polyacrylamide magnetic beads as an antigen. The antibody concentrations were expressed as optical density units (ODU) and were considered positive if the cutoff value $(M+2 \sigma$ of the reference group, 0.050 ODU) was exceeded. The results were expressed as mean $\pm \sigma$, differences were considered significant when $p<0.05$. Pearson correlation coefficient $(r)$ was also used.

Results: 40 healthy persons (29 mans and 11 women), and 95 female patients with RA and the neurological signs, appeared during active phase of the disease, were recruited for this study. Mean age of the healthy controls was $36 \pm 7$ years, and for the RA group it was equal to $55 \pm 11$ years. Mean RA duration was $4.2 \pm 2.9$ years. 13 patients had low, 52 - moderate, and 8 - high disease activity. The most common types of neurological involvement were mononeuropathy $(n=29)$, polyneuropathy $(n=65)$, radiculopathy $(n=80)$; cervicocranialgias $(n=51)$, and trigeminal neuralgias $(n=14)$. The symptoms of central nervous system damage (TIA, seizures, cerebellar ataxia, dysarthria) were found in 21 patients. In RA group, anti-S-100 protein antibodies were detected in 11 (32.4\%) cases, with mean concentration $0.078 \pm 0.028$ ODU. The patients with different neurological signs had mean anti-S-100 protein antibody concentration $0.138 \pm 0.046 \mathrm{ODU}$, the subgroup without any neurological signs had $0.060 \pm 0.024$ ODU $(p=0.022)$. In all cases analyzed index correlated with the degree of activity of the pathological process. High levels of antibodies to S-100 protein in RA associated with central nervous system (CNS) and peripheral nervous system (PNS).

Conclusions: We found an association between neurological involvement in RA and elevation of anti-S-100 protein antibody concentrations. These findings give us an opportunity to improve the diagnosis of minor neurological damage in RA and thus to make more precise adjustment of the treatment.

References:

[1] Baillet A. S100A8, S100A9 and S100A12 proteins in rheumatoid arthritis. Rev

Med Interne. 2010 Jun;31(6):458-61.

Disclosure of Interest: None declared

DOI: 10.1136/annrheumdis-2017-eular.3123

\section{AB0229 DOES EXPRESSION LEVEL OF VIP AND ITS RECEPTORS CORRELATED WITH DISEASE SEVERITY IN EARLY ARTHRITIS?}

I.V. Seoane ${ }^{1}$, A. Lamana ${ }^{2}$, M. Carrión ${ }^{1}$, Y. Juarranz ${ }^{1}$, R. García-Vicuña ${ }^{2}$ I. González-Álvaro ${ }^{2}$, C. Martínez ${ }^{3}$, R.P. Gomariz ${ }^{1}{ }^{1}$ Dpto. Biología Celular, Facultad de Biología, Universidad Complutense de Madrid; ${ }^{2}$ Rheumatology Service, Hospital Universitario de la Princesa, Instituto de Investigación Sanitaria Princesa; ${ }^{3}$ Dpto. Biología Celular, Facultad de Medicina, Universidad Complutense de Madrid, Madrid, Spain

Background: Rheumatoid Arthritis (RA) is a heterogeneous disease, not only in the course but also in the response to treatment (1). So, a major challenge is the classification of patients according to the disease severity/mildness to apply customized therapeutic strategies. Low vasoactive intestinal peptide (VIP) serum levels are associated to a worse clinical course in Early Arthritis (EA) (2) and the expression of its receptor VPAC1 is associated with disease activity (3).

Objectives: To identify in an Early Arthritis cohort associations between clinical parameters of severity and serum VIP levels or expression of their receptors VPAC1 and VPAC2

Methods: We studied 212 patients from the PEARL (Princesa Early Arthritis Registry Longitudinal) study. Follow-up includes five visits $(0,6,12,24$ and 60 months) in which we collect demographic, clinical, laboratory, therapeutic and radiological data, as well as biological samples. Since there is not a global disease severity variable for RA, we stratified severity as follows: A) remission after two years of follow-up defined as SDAI <3.3 (4). B) Global Disease Assessment by Physician $>75$ th percentile of the population (severe disease) or $>25$ th percentile (mild disease). C) Median value in our population of the $\Delta$ erosion score (SvdH method assessed in hands) after two years of follow-up. VIP levels were determined by enzyme immunoassay and mRNA expression levels of VIP receptors in PBMCs by real-time PCR. To analyze the association between severity/mildness and the expression of VIP/VPAC we use several parametric and non-parametric hypothesis testing (t-test, ANOVA and Kruskal-Wallis) using Stata 12 for Windows (StataCorp PL, College Station, TX, USA).

Results: We observed a trend towards higher baseline VIP serum levels in patients who reached remission in terms of SDAI $(p=0.1169)$. Patients no achieving remission showed lower VPAC1 expression $(p=0.0494)$. Severe patients defined by GDAPh displayed a clear trend to lower VIP levels $(p=0.081)$. Those patients also exhibited significant lower VPAC1 expression levels $(\mathrm{p}=0.0276)$. Concerning bone erosion score, we did not observe a significant association with VIP levels; interestingly we found that those patients classified as "severe" by erosion score displayed lower VPAC1 expression levels $(\mathrm{p}=0.0722)$ and higher levels of VPAC2 $(\mathrm{p}=0.0253)$.

Conclusions: VIP serum levels and VPAC1 and 2 receptors expression are associated with a more severe phenotype in EA patients stratified by SDAl, GDAPh and bone erosion.

References:

[1] Firestein GS. Nature. 2003:423(6937):356-61.

[2] Martínez C, Ortiz AM, Juarranz Y, et al. PloS one. 2014;9(1):e85248.

[3] Seoane IV, Ortiz AM, Piris L, et al. PloS one. 2016;11(2):e0149141.

[4] Aletaha D, Smolen J. Clin Exp Rheumatol. 2005;23(5 Suppl 39):S100-8.

Acknowledgements: This work has been supported by Instituto de Salud Carlos III, Spain, cofinanced by FEDER, European Union: RETICS program, Red de Investigación en Inflamación y Enfermedades Reumáticas (RD16/0012/0008 (RPG) and RD16/0012/0011 (IGA) and the projects PI12/00758 (RPG), PI14/00477 (CMM) and PI14/00442 (IGA).

Disclosure of Interest: None declared

DOI: 10.1136/annrheumdis-2017-eular.4817

\section{AB0230 POLYMORPHISM OF CYTOTOXIC T-LYMPHOCYTE 4 +49A/G IS ASSOCIATED WITH EARLY PRESCRIBING THE BIOLOGICAL THERAPY IN ACTIVE EARLY RHEUMATOID ARTHRITIS PATIENTS (ERA PTS) REFRACTORY TO THE PREVIOUS SUBCUTANEOUS METHOTREXATE (SC MTX) MONOTHERAPY}

I. Guseva ${ }^{1}$, A.S. Avdeeva ${ }^{1}$, E.L. Luchikhina ${ }^{1}$, D.D. Abramov ${ }^{2}$, N.V. Demidova ${ }^{1}$, E.N. Alexandrova ${ }^{1}$, A.A. Novikov ${ }^{1}$, M.Y. Krylov ${ }^{1}$, E.Y. Samarkina ${ }^{1}$,

D.Y. Trofimov ${ }^{2}$, D.E. Karateev ${ }^{1}$, E.L. Nasonov ${ }^{1} .{ }^{1}$ V.A.Nasonova Research Institute of Rheumatology; ${ }^{2}$ NRC Institute of Immunology of FMBA of Russia, Moscow, Russian Federation, Moscow, Russian Federation

Background: Monotherapy with MTX is the first step of RA therapy as recommended by EULAR. According to "Treat to Target" (T2T) strategy principles insufficient response to MTX requires prompt switch to a combination therapy with biological agents.

Objectives: To find out whether polymorphisms of immune response genes are associated with early prescribing the biological treatment in eRA pts, refractory to the SC MTX monotherapy.

Methods: By January 2014, 210 pts with RA were included in the REMARCA study (Russian InvEstigation of MethotrexAte and biologics in eaRly aCtive inflammatory Arthritis), and 88 pts have passed the 12 months control point. All pts started SC MTX monotherapy with rapid up-titration of the dose from 10 to 25-30 mg/week. Therapy was revised every 3 months using DAS28, SDAI and CDAI indices. Combination with biologics (in most cases TNF inhibitors) 
was used in $57(65 \%)$ of pts at (median) 3 [3;6] month [1]. Retrospectively, 45 out of 88 active eRA pts ( 35 woman, mean age 53,$5 ; 46-59,5$ years, mean disease duration 7,$0 ; 4,0-11,5$ months, mean DAS28 5,8; 4,9-6,4, mean hs-CRP $27,0 ; 9,7-61,0 \mathrm{mg} / \mathrm{l})$ were selected to evaluate the changes in cytokine profile in MTX-naive pts during SC MTX and SC MTX + adalimumab (SC MTX+ADA) therapy [2]. These $45 \mathrm{pts}$ were genotyped for the following gene polymorphisms (SNPs): PTPN22 (+1858 C/T, rs2476601), CTLA4 (+49A/G, rs231775), TNFAIP3 (rs675520, rs6920220, rs10499194), IL6 (-174G/C, rs1800795), IL6R (+358A/C, rs8192284), TNFA (-308A/G, rs1800629), MCP1/ CCL2 (+2581A/G, rs1024611), IL10 (-592A/C, rs1800872, -1082 A/G, rs1800896), IL1A (-889C/T, rs1800587), IL1B (+3953C/T, rs1143634).

Results: By the end of 3 months of SC MTX therapy, 23 out of 45 eRA pts $(51,1 \%)$ adequately responded to SC MTX (EULAR criteria) and continued on SC MTX monotherapy. In 22 pts (48,9\%) SC MTX monotherapy failed, thus they were switched to SC MTX + ADA combination therapy. CTLA-4 gene polymorphism $(+49 \mathrm{~A} / \mathrm{G})$ was the only predictor for the administration of biological therapy in eRA pts, that was confirmed by a logistic regression analysis [OR=7,795\% Cl 1,4-40,9, $\mathrm{p}=0,017]$. The carriers of at least one $\mathrm{G}$ allele (AG/GG genotypes) received the biological therapy more often than subjects with AA genotype (20/22, 90,9\% and $13 / 23,56,5 \%$ respectively). Moreover, the CTLA-4 (+49A/G) genotypes (AG/GG vs AA respectively) were associated with DAS28 $(3,6 \pm 1,1$ and $4,6 \pm 1,6, p=0,04)$, the number of tender joints $(3,1 \pm 3,1$ and $7,1 \pm 5,1, p=0,016)$, the number of swollen joints $(2,7 \pm 2,5$ and $5,3 \pm 4,9 p=0,024)$, SDAl $(11,1 \pm 7,2$ and $20,2 \pm 12,1, p=0,018)$, CDAl $(10,6 \pm 7,1$ and $18,6 \pm 10,6, p=0,025)$ and CRP $(6,3 \pm 12,1$ and $21,8 \pm 37,1$ $\mathrm{p}=0,018$ ) values after 3 months of SC MTX monotherapy.

Conclusions: Our data suggest that CTLA-4 $(+49 \mathrm{~A} / \mathrm{G})$ genetic polymorphism is associated with more severe rheumatoid arthritis and may predict the need for early administration of biological therapy.

References:

[1] Karateev D., E. Luchikhina E., N. Demidova N. et al. Ann Rheum Dis 2014;73(Suppl2): 235-236.

[2] Avdeeva A.S. Novikov A. A, Aleksandrova E. N. et al. Ann Rheum Dis 2014;73(Suppl2): 215-216.

Disclosure of Interest: None declared

DOI: 10.1136/annrheumdis-2017-eular.3023

\section{AB0231 PHYSICIAN VISUAL ANALOG SCALE ESTIMATES FOR DAMAGE ARE HIGHER THAN FOR INFLAMMATION IN PATIENTS WITH OSTEOARTHRITIS AND ALSO IN PATIENTS WITH RHEUMATOID ARTHRITIS AT ALL LEVELS OF CLINICAL SEVERITY ACCORDING TO RAPID3}

I. Castrejon, J. Chua, J.A. Block, T. Pincus. Rheumatology, Rush University Medical Center, Chicago, United States

Background: A visual analog scale (VAS) to estimate the patient's global status (DOCGL) often is the most efficient of all 7 RA core data set measures to distinguish active from control treatments in clinical trials ${ }^{1}$. DOCGL is designed to assess inflammatory activity, but it may be influenced variably in different doctors by irreversible joint damage and/or distress. Therefore, 3 additional $0-10$ VAS have been developed to estimate levels of inflammation, damage, and distress that may impact DOCGL.

Objectives: To analyze 4 estimates for overall global, inflammation, damage and distress according to 4 RAPID3 (routine assessment of patient index data) severity categories in patients with RA or OA.

Methods: Patients seen at one academic clinical setting are assigned 4 0-10 VAS estimates: overall DOCGL, inflammation (reversible), damage (irreversible), and distress (symptoms explained by neither inflammation nor damage, eg, fibromyalgia). All patients complete a self-reported MDHAQ questionnaire as part of routine care. The MDHAQ includes $0-10$ scores for physical function (FN), pain (PN), patient global estimate (PATGL), compiled into a 0-30 RAPID3. Patients with a primary diagnosis of RA or OA according to their rheumatologists were included. The percentage of RA and OA patients in each RAPID3 severity category was compared according to mean DOCGL and the 3 subscale estimates using chi-square and ANOVA.

Results: The study included 232 patients with RA and 274 with OA. Patients with OA were older than RA patients $(66.5$ versus $57.3, p<0.001)$ and had higher scores for RAPID3 (14.4 vs 11.7, $p<0.001$ ). A higher percentage of patients with OA had high RAPID3 severity compared with RA patients (66\% vs $48 \%$, $\mathrm{p}<0.001$ ) (Table). DOCGL and each subscale estimate were higher according to each of 4 RAPID3 categories from remission to high severity in RA and OA (Table). The level of inflammation was higher in RA than in OA, but estimates for damage higher in OA than RA. However, estimates for damage were higher than for inflammation in RA in each RAPID3 category.

Conclusions: Physician VAS for inflammation, damage, and distress may supplement the overall physician global estimate as quantitative physician
Table 1. Mean and SD for the four physician estimates according to RAPID3 categories in RA and OA patients

\begin{tabular}{|c|c|c|c|c|c|}
\hline & \multicolumn{4}{|c|}{ RAPID3 Severity Categories } & \multirow[t]{2}{*}{$\mathrm{P}$} \\
\hline & Remission $(<3)$ & Low (3-6) & Moderate (6-12) & High $(>12)$ & \\
\hline \multirow{2}{*}{\multicolumn{6}{|c|}{$\begin{array}{c}\text { Rheumatoid Arthritis } \\
\text { Overall DOCGL }\end{array}$}} \\
\hline & & & & & \\
\hline (0-10 scale) & $1.7(1.4)$ & $2.7(1.5)$ & $3.3(1.4)$ & $5.1(1.9)$ & $<0.001$ \\
\hline Inflammation (0-10) & $1.3(1.9)$ & $1.4(1.8)$ & $1.6(1.3)$ & $3.3(2.5)$ & $<0.001$ \\
\hline Damage $(0-10)$ & $1.7(1.5)$ & $2.9(2.0)$ & $2.9(2.0)$ & $3.7(2.2)$ & $<0.001$ \\
\hline Distress $(0-10)$ & $0.2(0.7)$ & $0.3(0.8)$ & $0.4(0.9)$ & $1.6(2.4)$ & $<0.001$ \\
\hline Osteoarthritis & $\mathrm{N}=14(5 \%)$ & $\mathrm{N}=18(7 \%)$ & $\mathrm{N}=60(22 \%)$ & $\mathrm{N}=182(66 \%)$ & \\
\hline \multicolumn{6}{|l|}{ Overall DOCGL } \\
\hline (0-10 scale) & $1.3(1.2)$ & $2.5(0.8)$ & $3.2(1.4)$ & $4.7(1.6)$ & $<0.001$ \\
\hline Inflammation $(0-10)$ & $0.4(0.6)$ & $0.7(1.1)$ & $0.8(1.4)$ & $1.0(1.4)$ & 0.25 \\
\hline Damage $(0-10)$ & $2.5(1.5)$ & $3.0(0.9)$ & $3.5(1.5)$ & $4.5(1.8)$ & $<0.001$ \\
\hline Distress $(0-10)$ & $0.0(0.0)$ & $0.3(0.6)$ & $1.1(2.1)$ & $2.0(2.8)$ & $<0.001$ \\
\hline
\end{tabular}

estimates of reversible findings, irreversible findings, and distress to support clinical management decisions. Estimates of joint damage are higher in $O A$ than in RA, although higher than estimates of inflammation in both RA and OA, in patients in all 4 RAPID3 severity categories.

References:

[1] Pincus T, et al. Clin Exp Rheumatol 2014; 32 (Suppl. 85): S47-S54

Disclosure of Interest: I. Castrejon: None declared, J. Chua: None declared, J. Block: None declared, T. Pincus Shareholder of: Health Report Services, Inc DOI: 10.1136/annrheumdis-2017-eular.3556

\section{AB0232 MINIMAL CLINICALLY IMPORTANT IMPROVEMENT (MCII) OF RAPID3 (ROUTINE ASSESSMENT OF PATIENT INDEX DATA 3), AN INDEX OF ONLY PATIENT SELF-REPORT SCORES, PERFORMS SIMILARLY TO TRADITIONAL RHEUMATOID ARTHRITIS (RA) INDICES, DAS28 AND CDAI}

I. Castrejon ${ }^{1}$, M.M. Ward ${ }^{2}$, M.J. Bergman ${ }^{3}$, L.C. Guthrie ${ }^{2}$, M.I. Alba ${ }^{2}$, T. Pincus ${ }^{1} .{ }^{1}$ Rheumatology, Rush University Medical Center, Chicago; ${ }^{2}$ Intramural Research Program, NIAMS/NIH, Bethesda; ${ }^{3}$ Rheumatology, Taylor Hospital, Ridley Park, United States

Background: No single "gold standard" measure is available to assess patients with rheumatoid arthritis (RA) in clinical trials and routine care, as in hypertension, diabetes, and other diseases. Therefore, an index of several measures, such as a DAS28 (Disease Activity Score-28) and CDAI (Clinical Disease Activity Index), based on 7 RA core data set measures; is needed. However, the only quantitative data in many (most) patients in routine rheumatology care are laboratory test results. RAPID3 (routine assessment of patient index data), which includes only patient self-report scores, is considerably more feasible than DAS28 or CDAI for routine care, distinguishes active from control treatments in RA clinical trials similarly and is correlated significantly with these indices. A minimal clinically important improvement (MCII) to interpret changes in clinical trials and clinical care has not been established for RAPID3

Objectives: To estimate MCII of RAPID3, and compare results to MCIls of DAS28 and CDAI.

Methods: Post hoc analyses were performed of a reported longitudinal study of 250 patients with active RA (1). All 7 RA core data set measures were collected at baseline and after treatment escalation with prednisone 1 month later or with disease modifying medications or biologic agents 4 months later (1). Patient judgment of improvement in arthritis status was obtained as "improved", "the same" or "worsened", and analyzed in relation to changes in RAPID3, DAS28 and CDAI. RAPID3 is the sum of 3 0-10 measures: physical function on a HAQ recalculated from $0-3$ to $0-10$, pain and patient global estimate on $0-10$ VAS (visual analog scales), total $=0-30$. DAS28-ESR (erythrocyte sedimentation rate) and CDAI were computed as described in the literature. Changes in all indices, standardized response means (SRM), MClls as changes that had a specificity of 0.80 for improvement based on receiver-operating characteristic curves, and $\mathrm{MCII}$ as a proportion of the maximum score were computed.

Results: Among 250 patients, $167(66.8 \%)$ reported improvement. RA activity and SRMs improved similarly per the 3 indices (Table). ROC curve areas were $>0.77$ (Table). MClls with specificity for improvement of 0.80 were -3.5 for RAPID3, -1.17 for DAS28-ESR, and -12.5 for CDAl. MClls were in a similar range of $11.6 \%$ to $16.8 \%$ of maximum score (Table).

Conclusions: MCIls for RAPID3, DAS28, and CDAI were in a similar range. Knowledge concerning MCII thresholds can improve interpretation of data from clinical trials and routine clinical care.

References:

[1] Ward, M et al, Ann Rheum Dis 2015, 74:1691-1696.

Disclosure of Interest: I. Castrejon: None declared, M. Ward: None declared, M.

Abstract AB0232 - Table 1. Changes in rheumatoid arthritis activity measures during the study

\begin{tabular}{|c|c|c|c|c|c|c|c|}
\hline Measure (range) & Baseline & Follow-up & Mean (\%) change & SRM $(95 \% \mathrm{Cl})$ & ROC Curve Area $(95 \% \mathrm{Cl})$ & MCII $(95 \% \mathrm{Cl})$ & $\%$ of Total \\
\hline RAPID3 $(0-30)$ & $16.3 \pm 6.3$ & $11.1 \pm 6.7$ & $-5.2 \pm 6.5(32 \%)$ & $-0.79(-0.71,-0.88)$ & $0.80(0.74,0.86)$ & $-3.5(-2.9,-4.3)$ & $11.6 \%$ \\
\hline DAS28-ESR $(0-9.4)$ & $6.16 \pm 1.2$ & $4.8 \pm 1.38$ & $-1.31 \pm 1.34(21 \%)$ & $-0.98(-0.90,-1.07)$ & $0.77(0.71,0.82)$ & $-1.17(-1.36,-0.87)$ & $12.4 \%$ \\
\hline CDAI $(0-76)$ & $36.8 \pm 13.5$ & $23.0 \pm 13.6$ & $-13.7 \pm 14.1(37 \%)$ & $0.98(-0.90,-1.08)$ & $0.78(0.73,0.84)$ & $-12.5(-14.7,-10.5)$ & $16.4 \%$ \\
\hline
\end{tabular}

${ }^{*} \mathrm{SRM}=$ standardized response mean; $\mathrm{Cl}=$ confidence interval. 